\title{
PENGARUH EMPLOYER BRANDING DAN EMPLOYER VALUE PROPOSITION TERHADAP KOMITMEN ORGANISASI DOSEN TELKOM UNIVERSITY
}

\author{
Yuliani Rachma Putri ; Mohamad Syahriar Sugandi \\ Program Studi S1 Ilmu Komunikasi Fakultas Komunikasi dan Bisnis Universitas Telkom \\ Jl. Telekomunikasi No. 1 Terusan Buah Batu Bandung \\ Email: yuliani.nurrahman@gmail.com

\begin{abstract}
Abstrak
\end{abstract}
Telkom University sebagai salah satu institusi penyelenggara pendidikan tinggi swasta di Indonesia sebagai peleburan dari beberapa Institusi, namun sudah berada pada peringkat atas sebagai perguruan tinggi swasta yang diminati di Indonesia. Minat untuk menjadi bagian dari Telkom University tidak hanya untuk menjadi mahasiswa saja, melainkan untuk menjadi tenaga kerja atau tenaga pengajar di institusi ini. Brand Telkom yang digunakan yang sangat identik dengan PT. Telkom Indonesia sebagai penggagas awal berdirinya institusi ini, dimana brand tersebut sudah sangat dikenal secara nasional di Indonesia sebagai salah satu perusahaan BUMN terbesar yang masih kuat hingga saat ini selalu menjadi tujuan bagi para pencari kerja untuk melamar. Hal ini terjadi pula di lingkungan institusi pendidikan Telkom University, tidak sedikit tenaga kerja khususnya tenaga pengajar (dosen) yang memiliki keinginan untuk menjadi bagian dari Telkom University. Sebagai fakultas yang termuda di Telkom University, Fakultas Komunikasi dan Bisnis sejak awal berdiri mencoba memenuhi kebuthan tenaga pengajar (dosen) serta mengelola dosen yang sudah ada sebelumnya. Berdasarkan hal itu, maka perlu ditelaah jika seorang Dosen kemudian memilih fakultas Komunikasi dan Bisnis Telkom University sebagai salah satu perguruan tinggi untuk mengabdi dan menetap serta melakukan Tri Dharma atas nama perguruan tinggi tersebut apakah ada unsur bahwa pilihan yang diambil atas dasar brand yang dimiliki institusi (employer branding), ataukah karena segala sesuatu yang diberikan atau ditawarkan oleh institusi tersebut (employe value proposition) sehingga dosen berkomitmen terhadap institusi untuk tetap tinggal hingga masa pengabdian dinyatakan berakhir (organizational commitment).Dari hasil penelitian diketahui bahwa employer branding maupun employee value proposition mempengaruhi organization commitment. employer branding memiliki kontribusi yang lebih kecil dalam mempengaruhi organization commitment dibandingkan employee value proposition. Hal ini bisa dijabarkan dari hasil persamaan regresi yang didapat yaitu : $Y=32,269+0.322 X_{1}+0.740 X_{2}+$ e. yang 
memperlihatkan bahwa jika employer branding meningkat satu satuan maka organization commitment berkecenderungan meningkat pula sebesar 0,322 satuan. Sedangkan jika employee value proposition meningkat satu satuan maka tingkat organization commitment berkecenderungan meningkat pula sebesar 0,740 satuan. Dengan demikian terlihat bahwa employee value proposition memiliki pengaruh yang lebih besar terhadap organization commitment dibandingkan pengaruh employer branding terhadap organization commitment.

Kata Kunci: Employer branding, employer value proposition, komitmen organisasi 


\section{Latar Belakang}

Employer branding dapat diartikan sebagai usaha menyeluruh yang dilakukan oleh suatu organisasi atau perusahaan untuk mengkomunikasikan kepada karyawan baik yang dipekerjakan saat ini maupun kepada khalayak terutama calon karyawan dari organisasi atau perusahaan tersebut bahwa organisasi tersebut merupakan tempat yang layak serta diidamkan untuk bekerja. Employer branding diinterpretasikan sebagai proses membangun identitas perusahaan yang unik dan dapat dikenali sebagai pemberi kerja. Organisasi atau perusahaan juga perlu membangun Employee Value Proposition, yaitu menciptakan atau memberikan penawaran yang unik, menarik serta memiliki kekuatan untuk menarik karyawan agar tetap loyal dan dapat menarik calon pelamar untuk bergabung dalam organisasi ataupun perusahaan tersebut. Menciptakan Employer Branding maupun Employee Value Proposition dalam upaya membawa value bagi perusahaan tidak hanya berdampak pada penekanan angka turnover karyawan namun juga dapat membangun hubungan bagi karyawan untuk merasakan adanya ikatan dengan organisasi tersebut. Karyawan yang loyal dengan employer brand akan tetap berada dalam perusahaan tersebut.

Telkom University merupakan salah satu lembaga pendidikan tinggi yang memiliki citacita untuk mengabdi dan berkontribusi dalam pembangunan melalui layanan pendidikan, penelitian dan pengabdian masyarakat (Tri Dharma Perguruan Tinggi) yang didedikasikan untuk meningkatkan kualitas kehidupan bagi manusia. Akan tetapi di satu sisi Telkom University juga merupakan suatu organisasi yang tentunya menjalankan strategi, manajemen dan pengelolaan sumber daya-sumber daya yang dimiliki termasuk sumber daya manusia baik tenaga pengajar maupun staf penunjang lainnya. Untuk dapat mengelola dan mempertahankan sumber daya manusia di dalam institusi tidaklah mudah, apalagi untuk dunia akademis dimana tenaga pengajar yang umumnya disebut sebagai Dosen merupakan kalangan yang terkadang harus diberikan ruang gerak yang cukup dalam mengembangkan serta menjalankan kegiatan Tri Dharma nya. Dosen sebagai tenaga 
pengajar apalagi yang telah memiliki pengakuan sertifikasi secara nasional di bidang keahliannya akan memiliki kebebasan untuk memilih tempat mereka berafiliasi. Disinilah tantangan bagi Telkom University untuk tetap dapat mempertahankan tenaga pengajar (dosen) yang sudah ada serta menarik tenaga pengajar yang kompeten untuk dapat bergabung. Untuk itu perlu bagi Telkom University untuk menciptakan branding yang kuat serta menciptakan value proposition yang bisa ditawakan pada dosen tetap dan sebagai upaya sehingga dosen bersedia berkomitmen terhadap Universitas Telkom untuk tetap tinggal hingga masa pengabdian dinyatakan berakhir (organizational commitment).

\section{Rumusan Masalah}

1. Bagaimana startegi employee branding Telkom University berdasarkan penilaian dosen tetap?

2. Bagaimana employee value proposition yang ditawarkan Telkom University berdasarkan penilaian dosen tetap?

3. Bagaimana komitmen organisasi para dosen di lingkungan Telkom University?

4. Sejauh mana pengaruh employee branding terhadap komitmen organisasi dosen tetap di lingkungan Telkom University?

5. Sejauh mana pengaruh employee value proposition terhadap komitmen organisasi dosen tetap di lingkungan Telkom University?

6. Sejauh mana pengaruh employee branding dan employee value proposition secara simultan terhadap komitmen organisasi dosen tetap di lingkungan Telkom University?

\section{Tinjauan Teori}

\section{Employer Branding}

Konsep dari employer branding banyak digunakan untuk menarik karyawan prospektif atau mempertahankan karyawan eksisting dalam suatu organisiasi. Sullivan (2004) menyatakan; employer branding sebagai : a targeted, long-term strategy to manage the 
awareness and perceptions of employees, potential employees, and related stakeholders with regards to a particular firm. Berdasarkan pendapat Berthon, P.Ewing.M dan Hah, L.L (2005: 151) dimensi employer attractiveness terbagi sebagai berikut:

1. Interest Value: ketertarikan calon pegawai atau pelamar didasari karena kreativitas lingkungan kerja (The extent to which an individual is attracted to an employer because of the excitement and creativity of the work environment).

2. Social Value: ketertarikan berdasarkan lingkungan kerja dengan atmospir tim kerja yang baik (Attraction based on a collegial work environment with good team atmosphere).

3. Economic Value: ketertarikan atas dasar gaji dan tunjangan yang ditawarkan (Attraction based on salary and benefits).

4. Development Value: ketertarikan berdasarkan adanya penghargaan terhadap prestasi kerja serta jenjang karir yang jelas (Based on recognition of work and career enhancing opportunities).

5. Application Value: ketertarikan atas kesempatan untuk belajar secara positif di lingkungan kerja (The employees' ability to value what they have learnt to teach others and interact with customers in a way that is positive and humanitarian).

\subsection{Employee Value Proposition}

Employee Value Proposition mengarah kepada serangkaian program yang dilakukan organisasi atau ditawarkan organisasi dalam mempekerjakan karyawan.terdapat lima atribut saat menciptakan EVP:

1. Leadership: prospek dan keuntungan personal yang didapat dari hubungan kerja dengan pimpinan (current and prospective employees gain personal benefits from the relation to their leader).

2. Rewards: prospek dan keuntunganyang didapat dari kepuasan kerja serta kompensasi yang diberikan (current and prospective employees gain personal benefits of higher satisfaction and more enjoyment from work when the company provides both superior tangible and intangible rewards). 
3. Performance Evaluation: prospek dan keuntungan yang didapat dari penilaian kinerja yang adil,(current and prospective employees gain personal benefits from fair performance evaluation, company do base on their performance both individual or team).

4. Company: prospek dan keuntungan yang didapat dari reputasi perusahaan (current and prospective employees gain personal benefits from how far others outside company know of and admire of the company and its reputation. Also how far the reputation,culture, climate and environment of the firm matches with employees personal).

5. Job: prospek dan keuntungan yang didapatkan dari pekerjaan yang menarik, adanya desain kerja, rotasi dan kesempatan untuk pengembangan (current and prospective employees gain personal benefits of higher satisfaction and more enjoyment from work when the company provides interesting jobs with desirable levels of discretion, job design, job rotation, and actual growth opportunities and development).

(Febriana \& Welly, 2013:3)

\section{Organizational Commitment}

Mathis and Jakcson (in Sopiah, 2008: 156) memberikan pengertian komitmen organisasi sebagai berikut : "it is the degree to which employees believe in and accept organizational goals and objectives will remain or will not leave the organization". Selanjutnya juga dikatakan : “Organizational commitments are: (1) a strong desire to become a group member, (2) the willingness of high effort for theorganization, (3) a certain belief and acceptance of the values and objectives of the organization". (Luthans in Sutrisno, 2010:292). Meyer, Allen, and Smith in Sopiah (2008: 157) menyatakan bahwa ada tiga komponen dalam komitmen organisasi, yaitu: 
1. Affective commitment, muncul ketika pegawai menginginkan untuk menjadi bagian dari organisasi karena keterikatan secara emosional (occurs when employees want to be part of the organization because of the emotional attachment).

2. Continuance commitment, muncul ketika pegawai tetap tinggal di perusahaan karena mendapat gaji dan tunjangan serta keuntungan lain (occurs when employees remain in an organization because it takes salary and other benefits, or because the employee did not find another job).

3. Normative commitment, muncul dari diripegawai dimana dia tinggal karena komitmen serta merasa harus tinggal (arising from the values in employees' values in themselves. Employee stays to be the members of organization because of the awareness to organizational commitment is supposed to do).

\section{Pemodelan Masalah dan Metodologi \\ Pemodelan Masalah}

Dalam penelitian ini, yang akan ditelitia adalah pengaruh dari employer branding secara parsial terhadap komitmen organisasi, pengaruh employee value proposition secara parsial terhadap komitmen organisasi serta pengaruh employer branding dan employer value proposition secara simultan terhadap komitmen organisasi.

Berikut adalah pemodelan masalah penelitian:

\section{Gambar 4.1 Pemodelan Masalah}

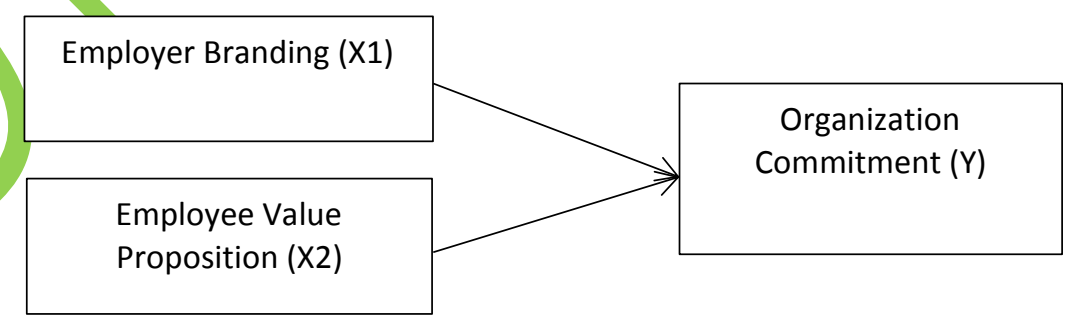




\section{Metodologi Penelitian}

\section{Populasi}

Menurut Sugiyono (2011 : 61), populasi adalah wilayah generalisasi yang terdiri atas; obyek/subyek yang mempunyai kuantitas dan karakteristik tertentu yang ditetapkan oleh peneliti untuk dipelajari dan kemudian ditarik kesimpulannya. Senada dengan pendapat Oei (2005 : 115) yang mengartikan populasi sebagai jumlah keseluruhan semua anggota yang diteliti. Di dalam penelitian ini, populasinya adalah dosen tetap di Fakultas Komunikasi dan Bisnis Telkom University.

\section{Sampel}

Penentuan sampel dalam penelitian ini menggunakan teknik nonprobability sampling. Menurut Sugiyono (2011 : 66), nonprobability sampling adalah teknik pengambilan sampel yang tidak memberi peluang atau kesempatan sama bagi setiap unsur atau anggota populasi untuk dipilih menjadi sampel. Dari jenis-jenis teknik nonprobability sampling, penulis menggunakan teknik purposive. Karena mengukur employee engagement dan komitmen dosen terhadap institusi maka diperlukan responden dengan masa kerja minimal 2 tahun, objek penelitian penulis (populasi) dalam penelitian ini adalah seluruh dosen tetap fakultas komunikasi dan bisnis yang sudah memiliki masa kerja lebih dari 2 tahun di Telkom University.

\section{Pengukuran dan Analisis Data}

Penelitian ini menggunakan skala ordinal. Sugiama (2008 : 79) menyatakan, skala ordinal adalah pemberian angka pada suatu objek yang menunjukan tingkatan. Pada skala ordinal mencakup sifat-sifat yang ada dalam skala nominal ditambah satu karakter khusus bagi skala ordinal, yakni selain angka yang diberikan mengandung arti sebagai label, juga angkaangka tersebut menunjukkan tingkatan. 
Skala likert digunakan dalam penelitian ini pada pembuatan kuesioner. Menurut Riduwan dan Sunarto (2010 : 20), skala likert digunakan untuk mengukur sikap, pendapat dan persepsi seseorang atau sekelompok tentang kejadian atau gejala sosial, dan menurut Sugiama (2008 : 98), skala likert adalah skala yang dirancang untuk menguji apakah responden sangat tidak setuju (strongly disagree) atau sangat setuju (strongly agree) terhadap objek psikologis yang dinilainya.

Variasi dari skala likert dilakukan dalam penelitian ini dimana penulis hanya menggunakan empat tingkatan skor yaitu STS, TS, S dan SS dan kata setuju diganti dengan 'sesuai'. Jawaban netral $(N)$ juga dihilangkan dengan alasan untuk mengurangi terjadinya pemusatan data

\section{Uji Hipotesis}

Untuk menguji kebenaran hipotesis yang akan diteliti, maka digunakan pengujian $\mathrm{t}$ dengan tingkat kesalahan dari hasil uji dua variabel sebesar 0,05 (5\%), serta menggunakan $\mathrm{dk}=\mathrm{n}-2$ dengan menggunakan rumus yang dijelaskan Sugiyono (2011: 187) :

Dengan ketentuan:

$$
t=\frac{r \sqrt{n-2}}{\sqrt{1-r^{2}}}
$$

Jika $t_{\text {hitung }}>t_{\text {tabel }}$ maka $\mathrm{HO}$ ditolak Jika $t_{\text {hitung }}<t_{\text {tabel }}$ maka HO diterima

\section{Koefisien Determinasi}

Penilaian terhadap koefisien determinasi bertujuan untuk melihat variasi kemampuan variabel bebas dalam menjelaskan pengaruhnya terhadap variabel terikat. Besarnya koefisien determinasi atau besarnya variasi disebabkan oleh $\mathrm{X}$ (variabel independen) terhadap Y (variabel dependen). Jika koefisien determinasi mendekati 0 maka tidak berpengaruh, jika koefisien determinasi mendekati 1 maka sangat berpengaruh. 


\section{Uji Korelasi Pearson}

Dalam teori probabilitas dan statistika, korelasi juga disebut koefisien korelasi, adalah nilai yang menunjukkan kekuatan dan arah hubungan linier antara dua peubah acak (random variabel). Tabel dibawah menjelaskan tentang nilai kekuatan dalam Korelasi Pearson:

Tabel 3.4. Nilai Kekuatan dalam Korelasi Pearson

\begin{tabular}{|l|l|}
\hline Nilai & Makna \\
\hline $0,00-0,19$ & Sangat rendah/ sangat lemah \\
\hline $0,20-0,39$ & Rendah / lemah \\
\hline $0,40-0,59$ & Sedang \\
\hline $0,60-0,79$ & Tinggi / kuat \\
\hline $0,80-1,00$ & Sangat tinggi / sangat kuat \\
\hline
\end{tabular}

Korelasi $\rho X, Y$ antara dua peubah acak $X$ dan $Y$ dengan nilai yang diharapkan $\mu X$ dan $\mu \mathrm{Y}$ dan simpangan baku $\sigma \mathrm{X}$ dan $\sigma \mathrm{Y}$ didefinisikan sebagai:

$$
\rho_{X, Y}=\frac{\operatorname{cov}(X, Y)}{\sigma_{X} \sigma_{Y}}=\frac{E\left(\left(X-\mu_{X}\right)\left(Y-\mu_{Y}\right)\right)}{\sigma_{X} \sigma_{Y}} .
$$

Karena $\mu X=E(X), \sigma X 2=E(X 2)-E 2(X)$ dan demikian pula untuk $Y$, maka dapat pula ditulis:

$$
\rho_{X, Y}=\frac{E(X Y)-E(X) E(Y)}{\sqrt{E\left(X^{2}\right)-E^{2}(X)} \sqrt{E\left(Y^{2}\right)-E^{2}(Y)}}
$$

\section{Uji Regresi Berganda}

Hipotesis penelitian yang diajukan akan diuji dengan menggunakan analisis regresi berganda. Dalam analisis tersebut terdiri dari variabel employer branding (X1) dan variabel employer value proposition (X2) sebagai variabel independen dan variabel organization commitment (Y) sebagai variabel dependen. Model persamaan liniernya dapat dilihat pada persamaan di bawah ini :

$$
\text { Model : } Y=b_{0}+b_{1} X_{1}+b_{2} X_{2}+e
$$




\section{Uji F}

Untuk menguji signifikansi pengaruh secara simultan dari variabel employer branding (X1) dan variabel employee value proposition (X2) terhadap variabel organization commitment (Y), maka dilakukan F-test dengan tingkat kepercayaan 95\%. Adapun hipotesis yang diajukan adalah:

Hipotesis :

$\mathrm{Ha} \quad$ :employer branding dan employer value proposition secara simultan memiliki pengaruh signifikan terhadap organization commitment.

Ho : employer branding dan employer value proposition secara simultan tidak memiliki pengaruh signifikan terhadap organization commitment

\section{Kriteria pengujian :}

a. Jika $F_{\text {hitung }}<F_{\text {tabel }}$ atau signifikansi $>0,05$; maka Ho diterima dan Ha ditolak serta hubungannya dinyatakan tidak signifikan.

b. Jika Fhitung $>F_{\text {tabel }}$ atau signifikansi $<0,05$; maka Ho ditolak dan Ha diterima serta hubungannya dinyatakan signifikan

4. Hasil Penelitian

\section{Uji Regresi Berganda}

Hipotesis penelitian yang diajukan akan diuji dengan menggunakan analisis korelasi linier sederhana. Dalam analisis tersebut terdiri dari variabel employer branding (X1) dan variabel employe value proposition (X2) sebagai variabel independen dan variabel organizational commitment $(\mathrm{Y})$ sebagai variabel dependen. Model persamaan liniernya dapat dilihat pada persamaan di bawah ini :

$$
\text { Model : } Y=b_{0}+b_{1} X_{1}+b_{2} X_{2}+e
$$


Tabel 5.1

Model Summary

\begin{tabular}{|l|l|l|c|c|}
\hline Model & R & R Square & $\begin{array}{l}\text { Adjusted } \\
\text { R Square }\end{array}$ & $\begin{array}{l}\text { Std. Error of } \\
\text { The Estimate }\end{array}$ \\
\hline 1 & $.663^{\mathrm{a}}$ & .417 & .403 & 5.91996 \\
\hline
\end{tabular}

a. Predicators : (Constant), X2 X1

Diperoleh koefisien determinasi multiple $: R^{2}=0.417=41,70 \%$. Secara deskriptif, pengaruh variable employer branding (X1) dan variable employee value proposition (X2) secara simultan terhadap variabel organization commitment $(Y)$ sebesar $41,70 \%$, dimana sebesar 58,30\% dijelaskan oleh faktor-faktor yang tidak dimasukkan ke dalam model.

\section{Uji F}

Untuk menguji signifikansi pengaruh secara simultan dari 84ariable employer branding (X1) dan 84 ariable employee value proposition (X2) secara simultan terhadap variabel organization commitment (Y) maka dilakukan F-test dengan tingkat kepercayaan 95\%.

Tabel 5.2

ANOVA $^{a}$

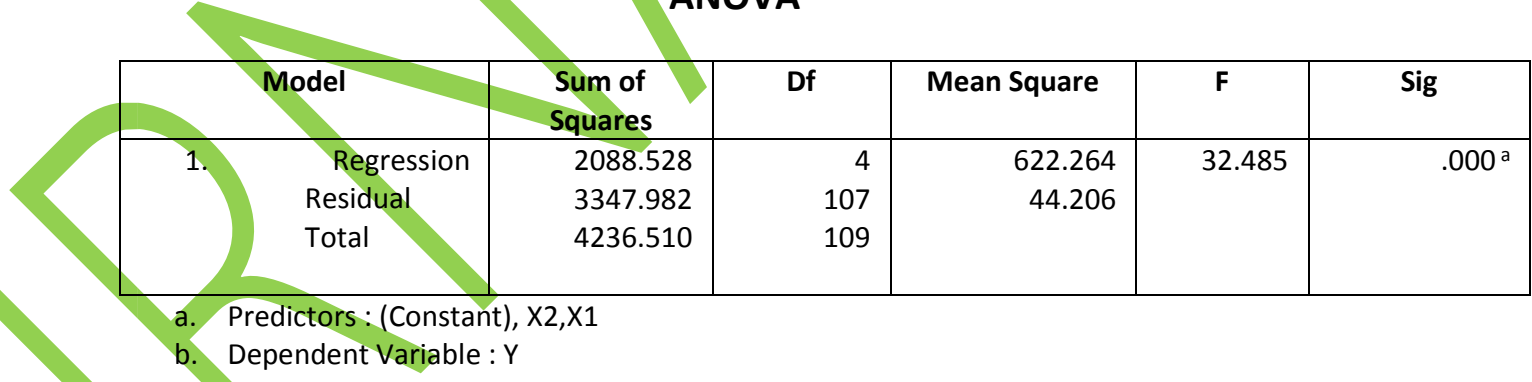

Berdasarkan uji hipotesis secara simultan diperoleh nilai $F=32,485$ dengan peluang kesalahan : $p$-value $(\mathrm{Sig})=0.05$. Nilai $F=32,485$ lebih besar dari $F_{\text {tabel }}=3,090187$ (pada $\alpha=$ $0,05$ dan $d f 1=2 ; d f 2=97)$ atau sama dengan $p$-value $=0.000$ lebih kecil dari $\alpha=0,05$. Hal ini menunjukkan bahwa Ho ditolak yang berarti variabel employer branding (X1) dan variabel employee value proposition (X2) berpengaruh secara simultan terhadap variabel organization commitment $(\mathrm{Y})$ pada taraf kesalahan $5 \%$. 


\section{Uji t}

Setelah dilakukan pengujian secara simultan menggunakan uji $\mathrm{F}$, selanjutnya dilakukan analisis dengan memakai uji t untuk menguji secara parsial masing-masing variabel independen yaitu variabel employer branding $(\mathrm{X} 1)$ dan variabel employee value proposition (X2) secara simultan terhadap variabel organization commitment (Y):

Tabel 5.3

Coefficients $^{\text {a }}$

\begin{tabular}{|c|c|c|c|c|c|c|}
\hline & \multirow[b]{2}{*}{ Model } & \multicolumn{2}{|c|}{$\begin{array}{c}\text { Unstandardized } \\
\text { Coeficient }\end{array}$} & \multirow{2}{*}{$\begin{array}{c}\text { Standardized } \\
\text { Coeficient }\end{array}$} & & \multirow[b]{2}{*}{ ig. } \\
\hline & & B & Std.Error & & & \\
\hline \multirow[t]{3}{*}{1} & (Constant) & 32.269 & 7.503 & & 4.424 & .001 \\
\hline & $\mathrm{X} 1$ & .322 & .183 & .367 & 3.684 & .009 \\
\hline & $x 2$ & .740 & .271 & .472 & 4.743 & .000 \\
\hline
\end{tabular}

a. Dependent Variable :Y

Pengujian secara parsial pengaruh employer branding (X1) terhadap organization commitment $(\mathrm{Y})$ diperoleh $\mathrm{t}\left(\mathrm{X}_{1}\right)$ sebesar 3,684 dengan peluang kesalahan : $\mathrm{p}$-value $(\mathrm{Sig})=$ 0.009. Nilai $t\left(X_{1}\right)=3,684$ lebih besar dari $t_{\text {tabel }}=1,984723$ (pada $\alpha=0,05$ ). Hal ini menunjukkan bahwa Ho ditolak yang berarti employer branding (X1) berpengaruh secara parsial terhadap organization commitment $(\mathrm{Y})$ pada taraf kesalahan $5 \%$.

Pengujian secara parsial pengaruh employee value proposition (X2) terhadap organization commitment $(\mathrm{Y})$ diperoleh $\mathrm{t}\left(\mathrm{X}_{2}\right)$ sebesar 4,743 dengan peluang kesalahan : $\mathrm{p}$-value $(\mathrm{Sig})=$ 0.000. Nilai $t\left(X_{2}\right)=4,743$ lebih besar dari $t_{\text {tabel }}=1,984723$ (pada $\alpha=0,05$ ). Hal ini menunjukkan bahwa Ho ditolak yang berarti employee value proposition (X2) berpengaruh secara parsial terhadap organization commitment $(\mathrm{Y})$ pada taraf kesalahan $5 \%$. 
Berdasarkan hasil pengujian secara simultan dan parsial, maka persamaan regresi berganda adalah sebagai berikut :

$$
Y=32,269+0.322 X_{1}+0.740 X_{2}+e
$$

Dimana :

- Konstanta $b_{0}=32,269$ : harga matematis dari skor $Y$ jika skor $X 1=$ Skor $X 2=0$

- Koefisien regresi $X_{1}: b_{1}=0,322$; jika skor $X 1$ meningkat satu satuan, pada kondisi skor $X 2$ konstan, maka Skor $Y$ berkecenderungan untuk meningkat sebesar 0,322 satuan.

- Koefisien regresi $X_{2}: b_{2}=0,740$; jika skor $X 2$ meningkat satu satuan, pada kondisi skor $X 1$ konstan, maka Skor $Y$ berkecenderungan untuk meningkat sebesar 0,740 satuan.

\section{Analisis Penelitian}

Berdasarkan hasil perhitungan sebelumnya maka jelas bahwa dosen selaku responden pada dasarnya menilai bahwa Telkom University memiliki employer branding yang cukup tinggi sehingga menjadi tujuan untuk bekerja, begitu juga dengan penawaran yang dilakukan Telkom University dan pandangan responden terhadap kondisi lembaga dimana secara employee value proposition Telkom University dinilai cukup memiliki daya 86 ias86 untuk dosen agar bekerja disana.

Jika secara parsial atau terpisah, dapat dilihat bahwa masing-masing baik itu employer branding maupun employee value proposition juga mempengaruhi organization commitment. Employer branding berdasarkan hasil perhitungan 86 ias 86 stic ternyata memiliki kontribusi yang lebih kecil dalam mempengaruhi organization commitment dibandingkan employee value proposition. Hal ini 86ias dijabarkan dari hasil persamaan regresi yang didapat yaitu : $Y=32,269+0.322 X_{1}+0.740 X_{2}+$ e. Persamaan tersebut memperlihatkan bahwa jika employer branding meningkat satu satuan maka organization commitment berkecenderungan meningkat pula sebesar 0,322 satuan. Sedangkan jika employee value proposition meningkat satu satuan maka tingkat organization commitment berkecenderungan meningkat pula sebesar 0,740 satuan. Dengan demikian terlihat bahwa 
employee value proposition memiliki pengaruh yang lebih besar terhadap organization commitment dibandingkan pengaruh employer branding terhadap organization commitment.

\section{Simpulan dan Saran}

\section{Simpulan}

Berdasarkan hasil penelitian dapat disimpulkan bahwa employer branding dan employee value proposition baik secara simultan maupun masing-masing secara parsial dirasakan oleh dosen yang menjadi responden penelitian memiliki pengaruh yang signifikan terhadap organization commitment di Fakultas Komunikasi dan Bisnis Telkom University. Secara simultan atau keseluruhan, pengaruh keduanya adalah $41,70 \%$ yaitu berada pada kategori rendah. Sedangkan 58,30\% dari organization commitment dipengaruhi hal-hal lain di luar variabel yang diteliti pada penelitian ini. Adapun dari dua variabel bebas yaitu employer branding dan employee value proposition, pengaruh yang lebih tinggi yang dirasakan responden berkontribusi terhadap variabel terikat yaitu organization commitment adalah employee value proposition dibandingkan dengan employer branding. Jadi apa yang ditawarkan oleh institusi kepada para dosen tetap selaku pegawai lebih berpengaruh dibandingkan daya tarik brand Telkom University dalam hal mempertahankan ataupun meningkatkan komitmen dosen terhadap institusi.

\section{Saran}

1. Bagi penelitian selanjutnya dapat mengembangkan dengan menambah variable yang belum diteliti dalam penelitian contohnya dengan menambahkan variable employee engagement selaku moderating.

2. Bagi penelitian selanjutnya dapat memperluas cakupan penelitian dengan menambah jumlah responden dari seluruh fakultas yang ada di Telkom University. 


\section{DAFTAR PUSTAKA}

Aloo, Victoria Akinyi, Moronge, Makori. "The Effects of Employee Value Proposition on Performance of Commercial Banks in Kenya". European Journal of Business Management. Vol.2, Issue 1, 2014

Berthon, P.Ewing.M and Hah, L.L . (2005). "Captivating Company: Dimensions of Attractiveness in Employer Branding". International Journal of Advertising, 24(2). pp. 151-172.

Febriana, Unggaran, Welly, John. (2013). “Create Brand Attractiveness to Support Attracting Strategy by Using Employee Value Proposition : Case Study at PT. Dirgantara Indonesia (Persero)". The Indonesian Journal of Business Administration. Vol. 2, No. 13, 2013:1590-1604. pp. 3.

Markos, Solomon, Sridevi. M.Sandhya. (2010). "Employee Engagement: The Key to Improving Performance". International Journal of Business and Management Vol. 5, No. 12; December 2010

Riduan (2010). Metode dan Teknik Menyusun Tesis. Bandung, ALFABETA

Rivai, Veltzhal. 2005. Manajemen Sumber Daya Manusia untuk Perusahaan. Jakarta : Murai Kencana.

Shen, Ling Ling Tao Qing Peng, (2014),"Can Training Promote Employee Organizational Commitment? The Effect of Employability and Expectation Value". Nankai Business Review International. Vol. 5 Iss 2 pp. 162 -186.

Sokro, Evans. (2012). "Impact of Employer Branding on Employee Attraction and Retention". European Journal of Business and Management. ISSN 2222-1905. Vol 4, No.18, 2012. pp.2.

Sopiah. (2008). Perilaku Organisasi. Yogyakarta : CV.Andi Offset

Sugiyono Wibowo, 2004, Staistik untuk Penelitian dan Aplikasinya dengan SPSS ver.10.0 for Windows. Alfabeta, Bandung

Sutrisno, Edy. (2010). Budaya Organisasi (Ed.1) Jakarta: Kencana. 